\title{
Review of state-of-the-art decision support systems (DSSs) for prevention and suppression of forest fires
}

\author{
Stavros Sakellariou $^{1} \cdot$ Stergios Tampekis $^{1} \cdot$ Fani Samara $^{1} \cdot$ \\ Athanassios Sfougaris $^{2} \cdot$ Olga Christopoulou ${ }^{1}$
}

Received: 19 January 2016/Accepted: 20 July 2016/Published online: 20 June 2017

(c) The Author(s) 2017. This article is an open access publication

\begin{abstract}
Forest ecosystems are our priceless natural resource and are a key component of the global carbon budget. Forest fires can be a hazard to the viability and sustainable management of forests with consequences for natural and cultural environments, economies, and the life quality of local and regional populations. Thus, the selection of strategies to manage forest fires, while considering both functional and economic efficiency, is of primary importance. The use of decision support systems (DSSs) by managers of forest fires has rapidly increased. This has strengthened capacity to prevent and suppress forest fires while protecting human lives and property. DSSs are a tool that can benefit incident management and decision making and policy, especially for emergencies such as natural disasters. In this study we reviewed state-of-the-art DSSs that use: database management systems and mathematical/ economic algorithms for spatial optimization of firefighting forces; forest fire simulators and satellite technology for
\end{abstract}

Project funding: Significant part of this research was co-financed by the European Union (European Social Fund-ESF) and Greek national funds through the Operational Program "Education and Lifelong Learning" of the National Strategic Reference Framework (NSRF) Research Funding Program: Thales. Investing in knowledge society through the European Social Fund.

The online version is available at http://www.springerlink.com

Corresponding editor: Hu Yanbo.

Stavros Sakellariou

stasakel@gmail.com

1 Department of Planning and Regional Development, University of Thessaly, 38334 Volos, Greece

2 Department of Agriculture Crop Production and Rural Environment, University of Thessaly, 38446 Volos, Greece immediate detection and prediction of evolution of forest fires; GIS platforms that incorporate several tools to manipulate, process and analyze geographic data and develop strategic and operational plans.

Keywords Decision support systems - Fire behavior simulation · Forest fires - Geographic information system . Mathematical algorithms · Risk management

\section{Introduction}

Forest ecosystems are our priceless natural resource and are fundamental to the global carbon budget (IPCC 2007). Forests contain approximately $66 \%$ of the surface carbon and have potential to sequester increasing amounts of $\mathrm{CO}_{2}$ through time (Lu et al. 2006).

Destructive and recurrent forest fires (of high intensity) are one of the greatest hazards for the viability and sustainable development of forests, and have impacts on natural and cultural environments, and the economy and the quality of life of local and regional populations. Forest management can be focused on prevention of destructive forest fires with the objective of retaining stored carbon and contributing to the mitigation of climate change impacts from the $\mathrm{CO}_{2}$ emissions which result from large forest fires (Hurteau et al. 2008).

Forest fires can stem from either natural (lightning) or anthropogenic causes (carelessness, accidents, arson). Anthropogenic fires typically account for the greatest percentage of forest fires, especially in the Mediterranean region (Ager et al. 2014; Carmel et al. 2009; Christopoulou 2011; Demir et al. 2009; Dimitrakopoulos et al. 2011; Moreno 2014). In Greece, natural causes account for $2.2 \%$ of all wildfires, whereas anthropogenic causes account for 95\% (35\% derived from unknown/random reasons; $35 \%$ 
from negligence; $25 \%$ from intent ${ }^{1}$ ). Forest fires annually affect $1 \%$ of the global total forest area (Christopoulou 2011).

At the European Union (EU) level, for the reference year 2011, 55,543 fires affected a total of 269,081 ha of forest. During 2011 in Greece, 1613 forest fires (3\% of all forest fires occurred in the 5 most vulnerable ${ }^{2}$ regions of the EU) burned $29,144 \mathrm{ha}^{3}$ of forest (11\% of the overall burnt area of the same 5 most vulnerable regions). Eightynine of the forest fires in Greece burned more than 40 ha and, in total, burned 36,872 ha. From 1983 to 2008, fires in Greece burned 1,361,312 ha, for an annual average of $52,358 \mathrm{ha} ; 1465$ fire incidents, and fire intensity approaching 36 ha per incident (Tsagari et al. 2011). The area affected by forest fires covering more than 40 ha, corresponds to forests (45\%), protected natural areas (29\%) and farmland (26\%). Unfortunately, 32\% (11,849 ha) of the overall damaged land in 2011 affected areas that are part of the NATURA 2000 network (European Commission 2012b).

An annual average of 9.3 million ha were burned in Russia between 1996 and 2005, while in Canada 2 million ha are affected by fire annually (for the last four decades) (Flannigan et al. 2009).

Van der Werf et al. (2010) estimated the average global emissions from fires to be $2.0 \mathrm{Pg} \mathrm{C}$ per year for approximately 22 years (1997-2009). The greatest amount of emissions originated from Africa (52\%), followed by South America (15\%), equatorial Asia (10\%), the boreal region (9\%), and Australia (7\%). They also estimated that the major contribution to global fire carbon emissions derived from fires in grasslands and savannas (44\%), woodland $(16 \%)$ and forests (15\%) (ibid.).

In future, climate change could affect drought frequency and intensity, with follow-on impacts on fire frequency and intensity. Due to the increased demand for forest goods, there is potential for greater $\mathrm{CO}_{2}$ emissions perturbing even further the global carbon budget (Williams et al. 2007).

According to $\mathrm{Lu}$ et al. (2006), the mean annual carbon release caused by forest fires in China amounts to over 11 $\mathrm{Tg}$ per year. China is a large country and as a result, is characterized by spatial variability in the number and size of forest fires due to different local characteristics (e.g., climatic conditions, forest fuel) ( $\mathrm{Lu}$ et al. 2006).

On a smaller spatial scale, the five Mediterranean countries of Greece, Spain, France, Portugal and Italy on

\footnotetext{
${ }^{1}$ For instance, forest fires could stem from "land use conflicts, political reasons or terrorist acts, complex proprietary regimes, shepherds and accumulated flammable forest material" (Christopoulou 2011).

2 Portugal, Spain, France, Italy and Greece.

3 The share of forest land corresponds to 19,348 ha and the share of non-forest land amounts to 9796 ha (European Commission 2012b).
}

average produce estimated annual $\mathrm{CO}_{2}$ emissions ranging from 358,509 to 5,816,367 $\mathrm{Mg} \mathrm{CO}_{2}$ (Vilen and Fernandes 2011). In a study using the Forest Carbon and Emissions Model (FCEM) to analyze the impact of four (2007) catastrophic fires in California (USA) on greenhouse gas emissions and opportunities to prevent and adverse environmental and climate impacts, Bonnicksen (2008) estimated that these wildfires burned over $586 \mathrm{~km}^{2}$ of forestland and emitted an estimated 9.5 million tons of greenhouse gases, without taking into account the post-fire impacts. This means that if the decay process after fires were considered, the estimated total emissions could reach 38 million tons of greenhouse gases (Bonnicksen 2008).

From a financial perspective, Greece in 2007 suffered a destructive fire event and losses (affecting about 500,000 people) were estimated at $1.91 €$ to $3 €$ billion (Mitsakis et al. 2014). In Wales, the economic cost from grass fires reached $4.5 £$ million (Forestry Commission 2014). In Turkey in 1999, forest fire damage cost about US $\$ 10$ million (European Commission 2014), demonstrating the economic impact but not addressing the social cost (e.g., loss of human lives).

From a socioeconomic standpoint, forest fires can have multiple impacts on the structure of society. The following statistical data highlight the significance of such impacts. Rabade and Aragoneses (2008) reported that during 1991-2003 in Spain, fires caused 59 people to be fatally injured and 118 people to be wounded, while there were occasions of massive evacuations relocating 41,752 people. Further, 169 dwellings were strongly or slightly affected by forest fires. Major problems resulted for electricity and water supply networks, while several road segments were blocked due to direct and indirect forest fire impacts (ibid.). Morton et al. (2003) listed wildfire impacts from 10 case studies in USA. Fire impacts included: the financial cost for fire suppression, which ranged from US\$120,000 to 150 million; the destruction of more than 130 dwellings; the loss of protected areas for valuable species of flora and fauna; damage to large numbers of public facilities and infrastructure; evacuation incidents of thousands of people; reduced tourist arrivals and income to service providers; timber damage; cultural and archaeological locations and premises were damaged and require restoration and resources; and health impacts due to smoke that affected millions of people (Morton et al. 2003). Canadian citizens have experienced similar consequences with costly damage to infrastructure and premises. Around $33 \%$ of particulate matter (PM) emissions are derived from forest fires (University of Alberta 2006).

For the above reasons, the selection of strategies to manage forest fire, while taking into consideration both functional and economic efficiency, is of primary importance. To this end, several versions of DSSs are fully 
integrated with GIS platforms that incorporate tools to manipulate, process and analyze geographic data. Some DSSs are totally web-based and include forest fire simulators and satellite technology tools for immediate detection and prediction of evolution of forest fires. Others are constructed on database management systems and/or mathematical or economic algorithms for spatial optimization purposes, so that they can support fire managers. Use of DSSs enhances the capacity of fire managers to prevent and suppress forest fires and reduce their impacts on natural and built environments and on human life.

\section{Characteristics of DSSs and their contribution to global forest fire management}

\section{Structural elements of DSSs}

DSSs are valuable tools for prevention and management of forest fires and are globally adopted at growing rates. The basic models-subsystems which comprise the structural elements for managing forest fires, and most DSSs use, are the following (Bonazountas et al. 2007; Dimopoulou and Giannikos 2004; European Commission 2012a; Giovando et al. 2013; Glasa 2009; Gumusay and Sahin 2009; Kalabokidis et al. 2012; Keramitsoglou et al. 2004; Lee et al. 2002, 2010; Noonan-Wright et al. 2011; Wybo 1998):

- Retrieval, analysis, update, edit and prediction models of geospatial (geomorphology-topography, socioeconomic and environmental data), meteorological and satellite data,

- Risk indexes and thematic maps (past fire incidents, moisture data) of indigenous vegetation and forest fuel,

- Fire propagation and behavior models and

- Use of interactive programs for the preparation, planning, coordination and prompt dispatch of forces of fire departments (human force, number and kind of fire machinery-land or aerial forces or even a combination).

\section{DSSs based on database management systems and mathematical/economic algorithms}

One of the first DSSs to exploit the usage of several technological tools and the precursor of the subsequent and technologically advanced DSSs for prevention and fighting of forest fires is the application of Wybo (1998). The key in that system is that the DSS incorporates in its databases a certain number of pre-processed scenarios which correspond to specific fire incidents. This eliminates the need to compose new scenarios from scratch, if, for example, new meteorological data are received. Hence, valuable time is saved during the process of monitoring, management and fighting of each fire incident in real time. Furthermore, this system contains integrated feedback, where the manager has the ability to produce or modify/update the pre-existing scenarios (according to new input). The new scenarios can, in turn, be applied to similar fire incidents in future. The subsystem of this DSS might divide the case study into smaller and specific subareas on the basis of fire risk level and the desired protection level of each identified district according to its local characteristics (for example the ecological value) (Wybo 1998). A given area can be divided into Fire Management Units, each with its own prescribed management strategy. This feature tailors responses to natural conditions while improving organization and management of information. This is especially useful when there are complex site conditions such as high biodiversity, difficulties in management of forest fuel. The importance of forming fire management units is obvious, especially in cases where fires cross more than one administrative region. This policy is used in USA, where it is referred to as Unified Command: (1) general aims and priorities are determined; (2) confrontation strategies and alternative solutions are established; (3) better coordination among agencies is targeted; (4) the best usage and allocation of available forces is achieved. All the above, including the avoidance of overlap between agencies saves resources and improves the effectiveness of fighting similar fire incidents (National Interagency Fire Center 2013).

Dimopoulou and Giannikos (2004) used an integrated system for forest fire control. This consisted of a geographic information system (GIS) module, a mathematical programing (MP) module, and a simulation model. A database provided the necessary spatial information. The optimal allocation of the fire department units (including amounts and types of forces) is estimated so that the firefighting authorities will be prepared to locate the fire and act within $10 \mathrm{~min}$ (time limit based on international standards) to any possible forest fire. Afterwards, the model of fire behavior "sends" new input, which is based on fire evolution (e.g., fire engines not available, natural barriers across main roads), to the subsystem of mathematical programming, enabling managers to deploy available firefighting resources within a specified time limit (Dimopoulou and Giannikos 2004).

Bonazountas et al. (2007) improved on the basic structural elements of DSS by adopting an additional model of socioeconomic factors (e.g., demography, tourism). These factors could affect the combustion risk levels. A thematic map is an output of this model. The probabilistic model contributes to the process, so that managers could plan the best allocation of the resources (firemen, land and aerial fire engines). An effectiveness analysis is carried out of the resources (human force, number and type of fire 
machinery, estimation of the time needed for fire brigades to reach the fire). Moreover, restrictions such as topography, strong winds, low visibility due to smoke, or the limits of economic resources are taken into account and the aims and strategies are adjusted accordingly. Another useful component of this model is estimation of economic cost for the maintenance of fire infrastructure and the fire mission, and for the overall burnt area. This is combined with an additional index which incorporates the land values of fire unit. Hence, it is possible to adopt specific management for particular geographical zones (Bonazountas et al. 2007).

Mavsar et al. (2012) reviewed the economic theory governing four fire management DSSs used in America and Europe. They used the "theoretical foundations of the efficiency analysis" of fire management measures to investigate the DSSs models' level of performance. They investigated the following four DSSs models: (1) Leopards model (Canada), (2) Kitral model (Chile), (3) Sinami model (Spain) and (4) Fire Program Analysis-FPA (USA). Of the four DSSs models they reviewed, the Sinami model based on $\mathrm{C}+\mathrm{NVC}^{4}$ was considered the best, since it helps fire managers perform an economic analysis of their investments (e.g., fire resources spatial allocation efficiency). The Sinami model incorporates economic impacts of fires (both negative and positive) in the stream of products and services generated from forest lands (Mavsar et al. 2012).

\section{DSSs based on fire behavior simulators}

The foundation of fire simulation lies in Rothermel's (1972) mathematical models for estimating fire spread. He also developed models for predicting crown fire behavior (Rothermel 1991). These fire models are integral parts of many contemporary fire simulation models such as Farsite, highlighting their contribution and significance to forest fire science.

Farsite is a deterministic fire simulation software that uses the principles of the "elliptical growth model of forest fire fronts" developed by Richards (1990). Farsite has three main uses: simulation of past fires, simulation of active fires, and simulation of potential fires. Analysis of past fires shows how the simulator reproduces known fire growth patterns, which is crucial in building confidence for using the simulator to project growth of active fires (Finney 1994). Fire behavior models included in Farsite calculate surface and crown fire behaviors as wells as fire acceleration, spotting from torching fires, and fuel moisture (Finney 1998). Since Farsite relies on the outputs of the above

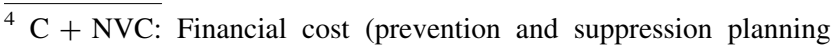
expenditures) + net value among destructive and beneficial implications of forest fires (Mavsar et al. 2012).
}

subsystems, the fire polygon is expanded beginning from an ignition point which is evolved according to the influence of wind and slope dimensions as well as the fire spread rate and time step. Geomorphological, meteorological, fuels and wind characteristics of the study area constitute the primary inputs of the model. Fire perimeters, fire spread and intensity are the main outputs of each simulation (Finney 2004). Many applications of Farsite have been implemented in different areas with the adjustments needed for local characteristics and for a number of specific purposes such as the influence of a fuel treatment process in fire evolution (Arca et al. 2007; Mutlu et al. 2008; Ryu et al. 2007; Schmidt et al. 2008; Stephens 1998; Stratton 2004).

Other researchers developed fire simulation systems using the Cellular Automata (CA) techniques. The primary inputs (topography, fuels characteristics and meteorological data) of these models and the previously mentioned fire behavior systems are quite similar. Karafyllidis and Thanailakis (1997) created such a model in a hypothetical mosaic of homogenous and heterogeneous fuels and they concluded that their model outputs closely resembled fire evolution in real situations. Improved versions of the Karafyllidis and Thanailakis (1997) model for more realistic representation of fire propagation were developed by Berjak and Hearne (2002) and Hernandez Encinas et al. (2007).

Yassemi et al. (2008) developed a fire behavior system that combined GIS capabilities with CA techniques. The degree of efficiency was considered highly satisfactory, since the Prometheus simulation (the Canadian fire growth model) results were comparable with the proposed-GIS and CA-model (Yassemi et al. 2008). Using a different approach, Vakalis et al. (2004a, b) used fuzzy logic and neural network modeling techniques in a mountainous area of Greece to estimate fire spread.

Prometheus is a deterministic fire simulation model which relies on the principles of the elliptical growth model of Richards (1990) and can be a valuable tool for rational and effective analysis and decision making. The primary inputs are derived from the geomorphology of the study area; the fuel types; the meteorological variables, and the corresponding Fire Weather Index System (FWI) values. The fire growth simulation is based on the Canadian Forest Fire Behavior Prediction System (CFFBPS) which permits the extended application of the model across the entire country. In addition, through this model, everybody may discover any piece of information related to the fire simulation, such as fire perimeter, rate of speed, surface and crown fuel consumption, fire intensity, or flame length. This detailed database is important, and all points on maps are attached with all the necessary information for burned and unburned areas as well as all the 
corresponding features (Tymstra et al. 2010). Prometheus fire growth model has been applied in many projects primarily focusing on the Canadian territory due to the matching of fuels with the CFFBPS (Tymstra et al. 2007; Yassemi et al. 2008).

Burn-P3 is a fire model that simulates and reckons the fire probability of huge fires. The model aims to assess the "relative likelihood of burn probability" for each geographical element of the study area, using the burn probability of pixels on given raster landscapes. This is realized by simulating the ignition point as well as the spread of every independent large fire. This software demands many inputs for efficient prediction. The inputs include fuel, topography, ignition points, fire zones (different fire regimes), weather zones, wind characteristics and the layer of firebreaks. Except for the spatial units, the model is structured with some environment requirements such as season; ignition cause; length of burn, and the daily fire weather characteristics. ${ }^{5}$ In addition to the burn probability (number of times each pixel affected by fire divided by the total number of fire simulations), Burn-P3 can produce supplementary outputs such as the size of the fires which took place at the simulation process; the ignition point geographically determined; the season; the number of spread-event days, as well as the area and the corresponding fuels burned (Western Partnership for Wildland Fire Science 2014). Burn-P3 software has been applied to many places in Canada (Beverly et al. 2009; Brown et al. 2010; Parisien et al. 2005, 2011, 2013). Burn-P3 relies on local (Canadian fuel database) fuel information because there is direct association of estimated fire behavior with each fuel type in the CFFBPS (Forestry Canada 1992; Hirsch 1996).

\section{DSSs based on geographical information systems platforms}

DSSs focused on Dijkstra's algorithm and network analysis

Dijkstra's algorithm (1959) is used to find the shortest path between two points and has many applications in a variety of fields. Dijkstra's algorithm was widely applied in forest fire simulations because, according to natural laws, a fire must follow a route which demands the minimum time. The reasoning is based on the fact that fire will ignite the nearest fuel as it evolves along the forest surface (Kourtz et al. 1977). Later, Lopes et al. (1995) combined the Rothermel's fire spread model with Dijkstra's algorithm in order to estimate fire propagation in mountainous topography.

\footnotetext{
$\overline{5}$ In addition to meteorological observations, Burn-P3 exploits the FWI System as developed by Van Wagner (1987).
}

One of the most widespread applications of Dijkstra's algorithm is network analysis, ${ }^{6}$ which commonly refers to road network characteristics. Many researchers have explored the optimal (shortest) path mainly for transportation and emergency purposes (Kai et al. 2014; Sui and Wang 2012; Rees 2004; Zhan 1997). Examples are finding shortest distances between fires and fire agencies to minimize time in transit (Hatfield et al. 2008). Dijkstra's algorithm has been improved to enhance the efficiency of the initial algorithm (Fan and Shi 2010; Rodriguez-Puente and Lazo-Cortes 2013).

Akay et al. (2011) combined the advantages of GIS and DSS and applied Network Analysis which incorporated four measures. First is identification of the nearest fire unit and estimation of the fastest route between each fire unit and the fire incident. The fire team taking the shortest route and the shortest time to arrival is activated (Condorelli and Mussumeci 2010; Gumusay and Sahin 2009; Keramitsoglou et al. 2004). Second, the quickest route of each moving fire team is estimated in real time and if a barrier appears across a pre-chosen route (e.g., a landslide), a second-best alternative route is determined at the same time from the current point of every responding vehicle to the site of the fire (Condorelli and Mussumeci 2010; Ichoua et al. 2000; Keenan 2008). The third measure involves the spatial coverage (through buffering) of forest land from the current fire units. The key to this method is the critical time of response by each fire team to approach the district of fire. If this combination is inadequate (both in travel distance and time of response), then it is concluded that more fire brigades must be established, so that every possibility of fire spreading and its consequences may be limited. The fourth measure involves fire teams using aircraft (helicopter) because they cover areas inaccessible to land-based teams (Akay et al. 2011).

\section{DSSs focused on fire risk determination}

In Brazil, a valuable Web DSS was developed by Barbosa et al. (2010). It included fire hotspot locating services using satellite technology (locating sites that surpass $47^{\circ} \mathrm{C}$ ). It also enabled the development of vulnerability maps that consider the fire risk caused by anthropogenic or natural causes as well as the determination of fire spread factors (fuels, topography). The output of this map consists of several thematic maps such as land-use maps, topographic maps (slope and aspect), minimum and maximum temperature and humidity maps, rainfall, wind velocity and wind direction maps. Next, a process of risk assessment

\footnotetext{
${ }^{6}$ Network Analysis Toolbox is fully integrated into GIS. The most of the applications of network analysis toolbox are relied on the Dijkstra's algorithm.
} 
was followed, based on the contribution of the above characteristics to fire ignition and spread. Each characteristic was assigned to five risk levels (very low to very high) depending on the nature of the characteristic (the changeable fire risk level was depicted on each thematic map). Afterwards, an algorithm reckoned the risk degree of each geographic area and integrated the estimated risk levels into one final risk map. Finally, when a fire breaks out, this point is immediately assigned to the respective fire alarm which coincides with the pre-estimated risk level. The appropriate land and/or aerial forces are mobilized directly (according to the significance of a given fire alarm) resulting in faster response to fire incidents before they spread (Barbosa et al. 2010).

Focusing on the Euro-Mediterranean countries, Kalabokidis et al. (2012) developed an integrated DSS (AUTOHAZARD PRO DSS) that incorporates four components meteorology, geomorphology, automatic ignitions detection, and fire behavior based on study area characteristics (e.g., fuels). The first three components represent the index of fire ignition and, when the latter is paired with the index of fire behavior, produce the final fire risk index which incorporates the basic elements of fire environment in any area. The product of this procedure consists of six separate thematic maps and one integrated map, which is a valuable tool for the simulation process as well as for operational vigilance, effective prevention, and timely suppression of forest fires (Kalabokidis et al. 2012).

Due to the complexity of the spatial nature of events like forest fires, other researchers used multi-criteria analysis and decision making methods. They combined, for instance, Knowledge Discovery in Databases (KDD), artificial neural network, or fuzzy logic techniques with Analytical Hierarchy Process (AHP) and other multi-criteria evaluation techniques through GIS platforms. Their objective was to address spatially explicit, complicated problems and determine the potential forest fire risk (Chen et al. 2003, 2004; Dong et al. 2006; Iliadis et al. 2002; Jaiswal et al. 2002; Kaloudis et al. 2005; Lapucci et al. 2005; Power 2006; Sakellariou et al. 2015; Sharma et al. 2012; Temiz and Tecim 2009; Vadrevu et al. 2010).

Several methods for estimating forest fire risk are available. Many researchers compile spatial data derived either from agencies or satellite sources that relate to natural factors like fuel types and characteristics; topography; and anthropogenic factors such as proximity to urban and road networks. Afterwards, the relationship of each factor with fire risk is estimated (internal weighting) and finally, an external weighting is based on the degree of influence of each dimension on fire ignition and evolution. The overlay of these factors through GIS (multi-criteria analysis) yields a fire risk map for any given area (Dong et al. 2006; Jaiswal et al. 2002; Power 2006; Sakellariou et al. 2015).
Other authors have used similar methods incorporating fuzzy logic techniques to deal with uncertainties that are inherent to forest fires. Kaloudis et al. (2005) developed a fire risk index considering the following factors: fire incidence probability; fire intensity; fire severity probability; values at risk and sensitivity of values at risk. Iliadis et al. (2002) developed a fire risk classification of the administrative parts of Greece based on real fire statistics using fuzzy logic techniques. Sharma et al. (2012) used all the natural and anthropogenic factors mentioned above with AHP techniques for efficient forest fire risk determination.

\section{DSSs focused on fire risk assessment and immediate fire incident management}

According to Thompson and Calkin (2011) and Thompson et al. (2011, 2012), fire risk is rendered in mathematical terms by the equation: $E(N V C j)=\Sigma p(f i) R F j(f i)$, where "Net Value Change" (NVC) of each resource is calculated as the sum of burn possibilities multiplied by the "response function" of resource per fire intensity level. ${ }^{7}$ The corresponding detrimental or beneficial fire implications are reckoned in quantitative terms. Due to the fact that the quantification of certain types of resources (mainly natural resources) is often subjective, a second best solution is adopted. The (local) experts systems substitutes the determination of fire effects on resources without wasting valuable time in calculating complex reactions (reaction of each fuel type to fire effects) and as a result, strategies and tactics are adjusted according to the current conditions, and the optimum reaction scenario is chosen. Thus, negative repercussions are minimized in a timely manner. Instead of the NVC method, a "Total Change Equivalent" method is applied in which the affected area (ha) is estimated either destructively or beneficially. A drawback of this method is that it does not take into consideration the social preferences and agency priorities. To this end, multi-criteria analysis techniques are used to fill this analytical gap and each resource is assigned and weighted according to its relative significance (ibid.).

At larger geographic scale, especially the adopted DSS in the USA is of interest. Wildland Fire Decision Support

\footnotetext{
7 With the term Net Value Change (NVC) is defined the percentage change of each resource from the initial condition against fire effects. That is, some types of resources may be adjusted better than others against fires, so the fire implications may be either beneficial or detrimental in the long run. So, the equation elements define the burn probability of each pixel of any possible fire intensity level (conducting by a fire behavior simulation model), as well as the "response" of each resource against fire effects for any fire intensity level (an index that can be estimated by experts' systems). Finally, NVC is computed by the sum of the above equation for all potential fire intensity levels (Thompson and Calkin 2011; Thompson et al. 2011, 2012).
} 
System (WFDSS) is an interactive web-based system that includes fire modeling subsystems and economic tools to facilitate and optimize the decision making process during forest fires events (WFDSS 2016). The comparative advantage of the WFDSS is the integration of all previous management processes of wildfires into a unified system that can access all essential data and has additional tools for fiscal evaluation of past fire incidents. All procedures are manageable in real time, while they are supported directly via the internet from many agencies responsible for managing forest fires. Besides the basic structural elements of DSSs, WFDSS incorporates additional economic and environmental tools. In addition, risk assessment of crucial structures (natural resources and infrastructure ${ }^{8}$ ) is conducted and these resources are depicted in the fire evolution map based on fire intensity. The "Net Value Change" might be either beneficial or destructive, depending on fire intensity and the resource nature, and can be estimated if protection of high-value resources might call for aggressive suppression. Otherwise, agencies may control and use the fire effects for environmental purposes. The first fundamental element of this DSS is the fire simulation system (FSPro) which maps fire evolution, utilizing the "Minimum Travel Time Algorithm" in real time when needed. ${ }^{9}$ Mapped concentric circles present the predicted fire evolution possibilities in percentages. A crucial component of WFDSS is known as RAVAR (Risk Assessment of Values At Risk). RAVAR uses geospatial data, fire evolution and behavior predictions in combination with infrastructure locations to protect natural and cultural resources. RAVAR produces a comparative economic analysis so that the best possible scenario from environmental and socioeconomic perspective can be chosen. Finally, there are special tools which calculate concentrations of particulate matter $\mathrm{PM}_{2.5}$ and ozone for the estimation of air quality impacts. Other modules develop thematic maps depicting the orbit of smoke and its implications on human health (Calkin et al. 2011a, b; Noonan-Wright et al. 2011).

At a similar geographical scale, the EU information system (EFFIS-European Forest Fire Information System) includes several innovative and valuable functions. EFFIS maps areas damaged by forest fires greater than 30 ha in area. This enables assessment of the extent and type of these catastrophes. EFFIS information is landsourced rather than remotely sensed. The significance is apparent when natural barriers (cloudy weather) or technical restrictions preclude retrieval of satellite images and

\footnotetext{
${ }^{8}$ Crucial structures and natural resources: Human settlements, transport, energy, oil and telecommunications infrastructure, habitat with endangered species, historical monuments) (Noonan-Wright et al. 2011).

${ }^{9}$ So that the strategy and tactics to be adjusted according to the current conditions in any given area.
}

location of active fire hotspots. EFFIS information is collected using a Rich Site Summary (RSS) method from several EU sources (Google news, blogs) at various geographical levels. A filtering and automatic geocoding procedure are conducted and each fire incident is located geographically. When EFFIS is combined with IDAS (IDAS provide information on population size and density, spatial allocation of infrastructure, and protected area locations) they offer capacity for comparative assessment of different forest fire incidents that occurred simultaneously in remote geographic locations. This enables managers to better prioritized fire firefighting resources based on population size and the amount and kind of infrastructure at risk (Giovando et al. 2013).

\section{Discussion}

The combination of operational research models and GIS enables management of the growing spectrum of complicated problems with massive and complex datasets. The use of GIS and new vehicle routing modules in DSSs can contribute to effective decision making (Condorelli and Mussumeci 2010; Ichoua et al. 2000; Keenan 2008). These technological advances have been successfully adopted by the Network Analysis tool and it is integrated into GIS platform and may contribute to more efficient fire management in future.

DSSs use not only GIS, but also satellite technology tools such as $L i D A R$, a reliable tool for rapid measurement and survey of vegetation characteristics, resulting in quicker and more effective management of fires; better post-fire recovery planning; ecosystem rehabilitation; restoration and the saving of fiscal resources (Wing et al. 2010).

A new technique is emerging, which is serving the same target of maximization of environmental safety and sound financial management and requires the active participation of citizens. Local geographical information is provided by citizens on a voluntary basis (VGI-Volunteered Geographic Information). This is an additional tool in crisis management that uses geospatial data in real time and provided by non-specialist users using devices such as smart phones or GPS receivers. Dissemination of information is conducted via internet. This tool can serve as an additional data source, supplementing satellite imagery and other online (internet) sources that are integrated in EFFIS. This can maximize overall system effectiveness (De Longueville et al. 2010).

DSSs can contribute to the quantification of complex interactions which take place during suppression of a forest fire and can facilitate the timely handling of critical situations. The positive key points of DSSs combined with 
management expertise can moderate the impacts of forest fires on the natural and cultural environment, and to the economic impact of every fire suppression mission (Mavsar et al. 2012).

DSSs are integrated information systems that incorporate state-of-the-art structural functions to help prevent and suppress forest fires. DSSs as an analytical and operational tool contributes to the mitigation of certain types of uncertainty which are involved in forest fires phenomenon. According to Thompson and Calkin (2011), such uncertainties could be referred to as linguistic uncertainty (notional confusion), variability uncertainty (e.g., meteorological conditions and natural elements), knowledge uncertainty (e.g., suppression effectiveness, response of natural resources to fires) as well as decision uncertainty (e.g., varying social preferences through time, agency interests and priorities conflicts) (Thompson and Calkin 2011).

\section{Concluding remarks}

Our review shows the worldwide evolution of DSSs based on mathematical/economic algorithms or GIS capabilities. Most DSSs are constructed from similar basic subsystems that aim at gaining full understanding through data analysis and then making the best management decisions within a narrow time frame. This is challenging in natural disaster management where minimizing environmental, social and economic impacts is the overall goal.

Acknowledgements The authors would like to thank Mr. P. Georgas for his contribution to the language review process as well as the reviewers for their valuable comments.

Open Access This article is distributed under the terms of the Creative Commons Attribution 4.0 International License (http://crea tivecommons.org/licenses/by/4.0/), which permits unrestricted use, distribution, and reproduction in any medium, provided you give appropriate credit to the original author(s) and the source, provide a link to the Creative Commons license, and indicate if changes were made.

\section{References}

Ager AA, Preisler HK, Arca B, Spano D, Salis M (2014) Wildfire risk estimation in the Mediterranean area. Environmetrics 25(6):384-396 (Special Issue: Wildland Fires)

Akay AE, Wing MG, Sivrikaya F, Sakar D (2011) A GIS-based decision support system for determining the shortest and safest route to forest fires: a case study in Mediterranean Region of Turkey. Environ Monit Assess 184:1391-1407

Arca B, Duce P, Laconi M, Pellizzaro G, Salis M, Spano D (2007) Evaluation of FARSITE simulator in Mediterranean maquis. Int J Wildland Fire 16(5):563-572
Barbosa MR, Sicoli Seoane JC, Guimaraes Buratto M, de Oliveira Santana, Dias L, Carvalho Raivel JP, Lobos Martins F (2010) Forest fire alert system: a GeoWeb GIS prioritization model considering land susceptibility and hotspots-a case study in the Carajás National Forest, Brazilian Amazon. Int J Geogr Inf Sci 24(6):873-901

Berjak SJ, Hearne JW (2002) An improved cellular automaton model for simulating fire in a spatially heterogeneous Savanna system. Ecol Model 148(2):133-151

Beverly JL, Herd EPK, Conner JCR (2009) Modeling fire susceptibility in west central Alberta, Canada. For Ecol Manag 258(7):1465-1478

Bonazountas M, Kallidromitou D, Kassomenos P, Passas N (2007) A decision support system for managing forest fire casualties. J Environ Manag 84:412-418

Bonnicksen TM (2008) Greenhouse gas emissions from four California wildfires: opportunities to prevent and reverse environmental and climate impacts. FCEM Report 2. The Forest Foundation, Auburn, California. p 19

Brown WJ, Jones BL, Lee JSW, Woolford DG, Wotton BM (2010) Forest fire risk assessment: An illustrative example from Ontario. J Probab Stat, Canada. doi:10.1155/2010/823018

Calkin DC, Finney MA, Ager AA, Thompson MP, Gebert KM (2011a) Progress towards and barriers to implementation of a risk framework for US federal wildland fire policy and decision making. For Policy Econ 13:378-389

Carmel Y, Paz S, Jahashan F, Shoshany M (2009) Assessing fire risk using Monte Carlo simulations of fire spread. For Ecol Manag 257:370-377

Chen K, Blong R, Jacobson C (2003) Towards an integrated approach to natural hazards risk assessment using GIS: with reference to bushfires. Environ Manag 31(4):546-560

Chen K, Jacobson C, Blong R (2004) Artificial neural networks for risk decision support in natural hazards: a case study of assessing the probability of house survival from bushfires. Environ Model Assess 9:189-199

Christopoulou OG (2011) Deforestation/reforestation in Mediterranean Europe: the case of Greece. Soil Erosion Studies. Dr. Danilo Godone (Ed.), ISBN: 978-953-307-710-9, InTech. doi: 10.5772/23466. http://www.intechopen.com/books/soil-erosionstudies/deforestation-reforestation-in-mediterranean-europe-thecase-of-greece; last accessed Apr 152013

Condorelli A, Mussumeci G (2010) GIS procedure to forecast and manage woodland fires. In: Konecny $\mathrm{M}$ et al (eds) Geographic information and cartography for risk and crisis management, lecture notes in geoinformation and cartography. Springer, Berlin. doi:10.1007/978-3-642-03442-8_7

Calkin DC, Thompson MP, Finney MA, Hyde KD (2011b) A realtime risk assessment tool supporting wildland fire decisionmaking. J For 109(5):274-280

De Longueville B, Annoni A, Schade S, Ostlaender N, Whitmore C (2010) Digital earth's nervous system for crisis events: real-time sensor web enablement of volunteered geographic information. Int J Digit Earth 3(3):242-259

Demir M, Kucukosmanoglu A, Hasdemir M, Ozturk T, Acar H (2009) Assessment of forest roads and firebreaks in Turkey. Afr $\mathrm{J}$ Biotechnol 8(18):4553-4561

Dijkstra EW (1959) A note on two problems on connection with graphs. Numer Math 1:269-271

Dimitrakopoulos AP, Bemmerzouk AM, Mitsopoulos ID (2011) Evaluation of the Canadian fire weather index system in an eastern Mediterranean environment. Meteorol Appl 18:83-93

Dimopoulou M, Giannikos I (2004) Towards an integrated framework for forest fire control. Eur J Oper Res 152:476-486 
Dong XU, Shao G, Dai L, Hao Z, Tang L, Wang H (2006) Mapping forest fire risk zones with spatial data and principal component analysis. Sci China Ser E 49:140-149

European Commission (2012a) European on-line Decision Support System for Forest Fire. http://ec.europa.eu/information_society/ activities/eten/cf/opdb/cf/project/index.cfm?mode=desc\&pro ject_ref=ETEN-26789\#pastnavigation; last accessed 14 Dec 2012

European Commission (2012b). Forest Fires in Europe, Middle East and North Africa 2011. http://www.fire.uni-freiburg.de/inven tory/database/EU-Forest-Fires-in-Europe-2011.pdf; last accessed 7 April 2013

European Commission (2014) Forest fires in the Mediterranean: a burning issue-WWF. http://ec.europa.eu/environment/forests/ pdf/meeting140504_wwffirstdocument.pdf; last accessed 28 Dec 2014

Fan D, Shi P (2010) Improvement of Dijkstra's algorithm and its application in route planning. In: Proceedings of 2010 seventh international conference on fuzzy systems and knowledge discovery (FSKD), 10-12 August, 2010. Yantai, Shandong. Volume: 4. pp. 1901-1904. doi: 10.1109/FSKD.2010.5569452

Finney MA (1994) Modeling the spread and behavior of prescribed natural fires. In: Proceedings of the 12th conference on fire and forest meteorology, 26-28 October, 1993; Jekyll Island, GA. Bethesda, MD: Society of American Foresters: 138-143

Finney MA (1998) FARSITE: Fire Area Simulator-Model development and evaluation. Res. Pap. RMRS-RP-4. Ogden, UT: USDA Forest Service, Rocky Mountain Research Station. p 47

Finney MA (2004) FARSITE: Fire Area Simulator-model development and evaluation (Revised). Res. Pap. RMRS-RP-4, Ogden, UT: U.S. Department of Agriculture, Forest Service, Rocky Mountain Research Station. p 47

Flannigan M, Stocks B, Turetsky M, Wotton M (2009) Impacts of climate change on fire activity and fire management in the circumboreal forest. Glob Change Biol 15:549-560

Forestry Canada Fire Danger Group (1992) Development and structure of the Canadian forest fire behavior prediction system. Ottawa (ON): Forestry Canada, Fire Danger Group and Science and Sustainable Development Directorate. p 64

Forestry Commission (2014) Forest fires and climate change. http:// www.forestry.gov.uk/fr/infd-7wlahk; last accessed 22 Dec 2014

Giovando C, Whitmore C, Camia A, San Miguel J, Boca R, Kucera J (2013) Geospatial support to forest fire crisis management at the European level. http://www.gdmc.nl/zlatanova/Gi4DM2010/ gi4dm/Pdf/p77.pdf; last accessed 16 Jan 2013

Glasa J (2009) Computer simulation and predicting dangerous forest fire behavior. Int J Math Comput Simul 3(2):65-72

Gumusay MU, Sahin K (2009) Visualization of forest fires interactively on the internet. Sci Res Essays 4(11):1163-1174

Hatfield DC, Wiitala MR, Wilson AE, Levy EJ (2008) A fast method for calculating emergency response times using travel resistance surfaces. In: Proceedings of the second international symposium on fire economics, planning, and policy: a global view. González-Cabán, Armando, tech. coord. Gen. Tech. Rep. PSW-GTR-208, Albany, CA: Pacific Southwest Research Station, Forest Service, U.S. Department of Agriculture. 720 p

Hernandez Encinas A, Hernandez Encinas L, Hoya White S, Martin del Rey A, Rodriguez Sanchez G (2007) Simulation of forest fire fronts using cellular automata. Adv Eng Softw 38:372-378

Hirsch KG (1996) Canadian Forest Fire Behavior Prediction (FBP) System: user's guide. Special Report 7. Natural Resources Canada, Canadian Forest Service

Hurteau MD, Koch GW, Hungate BA (2008) Carbon protection and fire risk reduction: toward a full accounting of forest carbon offsets. Front Ecol Environ 6:493-498
Ichoua S, Gendreau M, Potvin JY (2000) Diversion issues in real-time vehicle dispatching. Transp Sci 34(4):426-438

Iliadis LS, Papastavrou AK, Lefakis PD (2002) A computer-system that classifies the prefectures of Greece in forest fire risk zones using fuzzy sets. For Policy Econ 4:43-54

Intergovernmental Panel on Climate Change (IPCC) (2007) Climate change 2007: Synthesis report. Contribution of Working Groups I, II and III to the Fourth Assessment Report of the Intergovernmental Panel on Climate Change, (eds.) R. K. Pachauri and A. Reisinger. Geneva: IPCC. http://www.ipcc.ch/pdf/assess ment-report/ar4/syr/ar4_syr.pdf; last accessed 04 May 2016

Jaiswal RK, Mukherjee S, Raju KD, Saxena R (2002) Forest fire risk zone mapping from satellite imagery and GIS. Int J Appl Earth Obs Geoinf 4:1-10

Kai N, Zhang YT, Ma YP (2014) Shortest path analysis based on Dijkstra's algorithm in emergency response system. IJEECS 12(5):3476-3482

Kalabokidis K, Xanthopoulos G, Moore P, Caballero D, Kallos G, Llorens J, Roussou O, Vasilakos C (2012) Decision support system for forest fire protection in the Euro-Mediterranean region. Eur J For Res 131(3):597-608

Kaloudis S, Tocatlidou A, Lorentzos NA, Sideridis AB, Karteris M (2005) Assessing wildfire destruction danger: a decision support system incorporating uncertainty. Ecol Model 181:25-38

Karafyllidis I, Thanailakis A (1997) A model for predicting forest fire spreading using cellular automata. Ecol Model 99:87-97

Keenan P (2008) Modelling vehicle routing in GIS. Oper Res $8: 201-218$

Keramitsoglou I, Kiranoudis C, Sarimveis H, Sifakis N (2004) A multidisciplinary decision support system for forest fire crisis management. Environ Manag 33(2):212-225

Kourtz P, Nozaki S, O’ Regan WG (1977) Forest fires in the computera model to predict the perimeter location of a forest fire. Information Report FF-X-65. Fisheries and Environment Canada

Lapucci A, Lombardo S, Petri M, Santucci A (2005) A KDD based multicriteria decision making model for fire risk evaluation. In: Conference proceedings on 8th AGILE conference on GIScience. Association Geographic Information Laboratories Europe. 26-28 May 2005. Estoril, Portugal

Lee BS, Alexander ME, Hawkes BC, Lynham TJ, Stocks BJ, Englefield P (2002) Information systems in support of wildland fire management decision making in Canada. Comput Electron Agric 37:185-198

Lee H, Lim S, Paik H (2010) An assessment of fire-damaged forest using spatial analysis techniques. J Spat Sci 55(2):289-301

Lopes AMG, Sousa ACM, Viegas DX (1995) Numerical simulation of turbulent flow and fire propagation in complex topography. Numer Heat Transf A Appl 7(5):229-253

Lu A, Tian H, Liu M, Liu J, Melillo JM (2006) Spatial and temporal patterns of carbon emissions from forest fires in China from 1950 to 2000. J Geophys Res 111:D05313. doi:10.1029/2005JD006198

Mavsar R, Caban AG, Varela E (2012) The state of development of fire management decision support systems in America and Europe. For Policy Econ 29:45-55

Mitsakis E, Stamos I, Papanikolaou A, Aifadopoulou G, Kontoes H (2014) Assessment of extreme weather events on transport networks: case study of the 2007 wildfires in Peloponnesus. Nat Hazards 72:87-107

Moreno JM (2014) Forest Fires under climate, social and economic changes in Europe, the Mediterranean and other fire-affected areas of the world. FUME. Lessons learned and outlook. http:// fumeproject.uclm.es/; last accessed 25 Oct 2014

Morton DC, Roessing ME, Camp AE, Tyrrell ML (2003) Assessing the Environmental, Social, and Economic Impacts of Wildfire. GISF Research Paper 001. Forest Health Initiative. Yale 
University. School of Forestry and Environmental Studies. Global Institute of Sustainable Forestry. 360 Prospect Street, New Haven, Connecticut 06511 USA

Mutlu M, Popescu SC, Zhao K (2008) Sensitivity analysis of fire behavior modeling with LIDAR-derived surface fuel maps. For Ecol Manag 256(3):289-294

National Interagency Fire Center (2013). Interagency Standards for Fire and Fire Aviation Operations. http://www.nifc.gov/PUB LICATIONS/redbook/2013/2013RedBook.pdf; last accessed 30 Jan 2013

Noonan-Wright EK, Opperman TS, Finney MA, Zimmerman TG, Seli RC, Elenz LM, Calkin DE, Fiedler JR (2011) Developing the US wildland fire decision support system. J Combust 2011: Article ID 168473. doi:10.1155/2011/168473

Parisien MA, Kafka VG, Hirsch KG, Todd JB, Lavoie SG, Maczek PD (2005) Mapping wildfire susceptibility with the BURN-P3 simulation model. Natural Resources Canada, Canadian Forest Service, Northern Forestry Center, Edmonton, Alberta. Information Report NOR-X-405

Parisien MA, Parks SA, Miller C, Krawchuk MA, Heathcott M, Moritz MA (2011) Contributions of ignitions, fuels, and weather to the spatial patterns of burn probability of a boreal landscape. Ecosystems 14:1141-1155

Parisien MA, Walker GR, Little JM, Simpson BN, Wang X, Perrakis DDB (2013) Considerations for modeling burn probability across landscapes with steep environmental gradients: an example from the Columbia Mountains, Canada. Nat Hazards 66:439-462

Power CJ (2006) A spatial decision support system for mapping bushfire hazard potential using remotely sensed data. In: Proceedings of Bushfire conference 2006-Life in a Fire-Prone Environment: Translating Science Into Practice. Brisbane, 6-9 June 2006

Rabade JM, Aragoneses C (2008) Social impact of large-scale forest fires. In: Proceedings of the second international symposium on fire economics, planning, and policy: a global view. GonzálezCabán, Armando, tech. coord. Gen. Tech. Rep. PSW-GTR-208, Albany, CA: Pacific Southwest Research Station, Forest Service, U.S. Department of Agriculture. $720 \mathrm{p}$

Rees DW (2004) Least-cost paths in mountainous terrain. Comput Geosci 30(3):203-209

Richards GD (1990) An elliptical growth model of forest fire fronts and its numerical solution. Int $J$ Numer Methods Eng 30:1163-1179

Rodriguez-Puente R, Lazo-Cortes MS (2013) Algorithm for shortest path search in Geographic Information Systems by using reduced graphs. SpringerPlus 2:291

Rothermel RC (1972) A mathematical model for predicting fire spread in wildland fuels. USDA For Serv Res Pap, INT-115

Rothermel RC (1991) Predicting behavior and size of crown fires in the northern Rocky Mountains. USDA For Serv Res Pap, INT-438

Ryu SR, Chen J, Zheng D, Lacroix JJ (2007) Relating surface fire spread to landscape structure: an application of FARSITE in a managed forest landscape. Landsc Urban Plan 83(4):275-283

Sakellariou S, Samara F, Tampekis S, Sfougaris A, Christopoulou O (2015) Targeting to an efficient prevention strategy of forest fires, estimating the fire hazard on islands. The case study of Thasos island, Greece. IJAENT 2(11):27-32

Schmidt DA, Taylor AH, Skinner CN (2008) The influence of fuels treatment and landscape arrangement on simulated fire behavior, Southern Cascade range, California. For Ecol Manag 255(8-9):3170-3184

Sharma LK, Kanga S, Nathawat MC, Sinha S, Pandey PC (2012) Fuzzy AHP for forest fire risk modeling. DPM 21(2):160-171

Stephens SL (1998) Evaluation of the effects of silvicultural and fuels treatments on potential fire behaviour in Sierra Nevada mixedconifer forests. For Ecol Manag 105(1-3):21-35
Stratton RD (2004) Assessing the effectiveness of landscape fuel treatments on fire growth and behavior. J For 102(7):32-40

Sui M, Wang WF (2012) Application of GIS best path algorithm in Harbin roads. World Rural Obs 4(1):86-90

Temiz N, Tecim V (2009) Spatial multi criteria decision making in forest fire fighting planning. Turkish Chamber of Mechanical Engineers. http://www.mmo.org.tr/resimler/dosya_ekler/ 340ab740e0e799b_ek.pdf?dergi=753; last accessed 12 Feb 2014

Thompson M, Calkin D (2011) Uncertainty and risk in wildland fire management: a review. J Environ Manag 92:1895-1909

Thompson MP, Calkin DE, Gilbertson-Day JW, Ager AA (2011) Advancing effects analysis for integrated, large-scale wildfire risk assessment. Environ Monit Assess 179:217-239

Thompson MP, Ager AA, Finney MA, Calkin DE, Vaillant NM (2012) The science and opportunity of wildfire risk assessment. Chapter 6: pp. 99-120 in the book « Novel Approaches and Their Applications in Risk Assessment », Edited by Yuzhou Luo, ISBN 978-953-51-0519-0, Publisher: InTech, Chapters published April 20, 2012 under CC BY 3.0 license. doi: 10.5772/ 2548. http://www.intechopen.com/books/novel-approaches-andtheir-applications-in-risk-assessment/advancements-in-inte grated-wildfire-risk-assessment; DOI: 10.5772/38210; last accessed 20 Sept 2013

Tsagari K, Karetsos G, Proutsos N (2011) Forest Fires in Greece, 1983-2008. WWF Hellas and NAGREF-IMFE and FPT (In Greek)

Tymstra C, Flannigan MD, Armitage OB, Logan K (2007) Impact of climate change on area burned in Alberta's boreal forest. Int J Wildland Fire 16(2):153-160

Tymstra C, Bryce RW, Wotton BM, Taylor SW, Armitage OB (2010) Development and structure of Prometheus: the Canadian Wildland Fire Growth Simulation Model. Nat Resour Can, Can For Serv, North For Cent, Edmonton, AB. Inf. Rep. NOR-X-417

University of Alberta (2006) Forest fires a huge cost to health. www. sciencedaily.com/releases/2006/08/060810211036.htm; last accessed 10 Nov 2015

Vadrevu KP, Eaturu A, Badarinath KVS (2010) Fire risk evaluation using multicriteria analysis-a case study. Environ Monit Assess 166:223-239

Vakalis D, Sarimveis H, Kiranoudis C, Alexandridis A, Bafas G (2004a) A GIS based operational system for wildland fire crisis management I. Mathematical modelling and simulation. Appl Math Model 28:389-410

Vakalis D, Sarimveis H, Kiranoudis C, Alexandridis A, Bafas G (2004b) A GIS based operational system for wildland fire crisis management II. System architecture and case studies. Mathematical modelling and simulation. Appl Math Model 28:411-425

Van der Werf GR, Randerson JT, Giglio L, Collatz GJ, Mu M, Kasibhatla PS, Morton DC, DeFries RS, Jin Y, Van Leeuwen TT (2010) Global fire emissions and the contribution of deforestation, savanna, forest, agricultural, and peat fires (1997-2009). Atmos Chem Phys 10:11707-11735

Van Wagner CE (1987) Development and Structure of the Canadian Forest Fire Weather Index System. Canadian Forestry Service. Forestry Technical Report 35. Ottawa

Vilen T, Fernandes PM (2011) Forest fires in Mediterranean countries: $\mathrm{CO}_{2}$ emissions and mitigation possibilities through prescribed burning. Environ Manag 48:558-567

Western Partnership for Wildland Fire Science (2014) Burn-P3. Burn Probability Model (Burn-P3, Version 4.3, User's Manual, 2014)

WFDSS (2016) Wildland Fire Decision Support System. http://wfdss. usgs.gov/wfdss/WFDSS_Home.shtml; last accessed 10 June 2016

Williams CA, Hanan NP, Neff JC, Scholes RJ, Berry JA, Denning AS, Baker DF (2007) Africa and the global carbon cycle. Carbon Balance Manag. doi:10.1186/1750-0680-2-3 
Wing MG, Eklund A, Sessions J (2010) Applying LiDAR technology for tree measurements in burned landscapes. Int J Wildland Fire 19:104-114

Wybo JL (1998) FMIS: a decision support system for forest fire prevention and fighting. IEEE Trans Eng Manag 45(2):127-131

Yassemi S, Dragicevic S, Schmidt M (2008) Design and implementation of an integrated GIS-based cellular automata model to characterize forest fire behavior. Ecol Model 210(1-2): $71-84$

Zhan BF (1997) Three fastest shortest path algorithms on real road networks: data structures and procedures. J Geogr Inf Decis Anal $1(1): 70-82$ 